\title{
Multiple Ways of Promoting Innovating Education for Vocational Colleges \\ Jitao $\mathrm{Du}^{1, \mathrm{a}}$ \\ ${ }^{1}$ Advanced Vocational Technical College ,Shanghai University of Engineering Science Hongkou, Shanghai, China \\ ajtjaster@126.com
}

\begin{abstract}
Scientific and technological innovation has become the key to improve the comprehensive national strength, and the talents are the cornerstone of scientific and technological innovation. Thus, the innovation quality is key to the innovative talents, the innovation cases education is foundation, the innovation atmosphere is the guarantee and the innovation achievements incentive is the power are discussed in this paper. The research results provide a reference for building Shanghai Science and Technology Innovation Center .
\end{abstract}

Keywords: vocational education, innovating atmosphere, innovating achievements incentive, innovation quality

\section{多途径推进职业院校学生的创新教育}

\author{
杜继涛 ${ }^{1, a}$ \\ 1 上海工程技术大学高等职业技术学院, 虹口, 上海, 中国 \\ adtjaster@126.com
}

中文摘要. 科技创新已经成为提高综合国力的关 键，而人才是科技创新的基石。文中通过创新素 质是创新人才培养的关键, 创新案例教育是创新 人才培养的基础、创新氛围是创新人才培养的保 证、创新成果激励是创新人才培养的动力进行了 论述，以期为职业院校创新教育提供参考，为上 海向科技创新中心进军提供支持，。

关键词:职业教育; 创新氛围; 创新成果; 创新素质

\section{1. 引言}

国务院总理李克强2014年10日在天津 梅江会展中心出席第八届夏季达沃斯论坛 开幕式, 并发表特别致辞, 指出, 我们要加 大科技创新力度, 更多地依靠科技进步调整 结构。培育壮大新产品、新业态, 加快发展
服务业、高技术产业、节能环保等新兴产业; 积极化解产能过剩矛盾, 走创新驱动和内生 增长之路。只要大力破除对个体和企业创新 的种种束缚, 形成 “人人创新”、“万众创 新” 的新局面，中国发展就能再上新水平 [1]。习总书记在沪考察调研时替上海下一 步转型发展找准 “牛鼻子”，加快向具有全 球影响力的科技创新中心进军。“当今世界, 科技创新已经成为提高综合国力的关键支 撑, 成为社会生产方式和生活方式变革进步 的强大引领，谁牵住了科技创新这个牛鼻 子, 谁走好了科技创新这步先手棋, 谁就能 占领先机、赢得优势。”创新是人类进步和 社会发展的前提，而创新是离不开人类的创 造性思维。正是由于人的创造性思维，才使 今天的世界充满生机和光辉[2][3]。教学改 革中的素质教育的核心是教会学生学习的 
方法, 交给学生打开知识宝库的钥匙。如何 有效培养和促使创新型人才的涌现, 是上海 向科技创新中心进军的关键。因此, 创新教 育既是人才培养的基础, 又是人才使用的需 要, 更是时代发展的必然。因此, 在职业学 校实施创新教育势在必行, 另外, 习近平主 席提出了建设 “中国梦” 的宏伟计划, 让国 人兴奋, 让教育工作者振奋和激动。围绕 “人人创新” “ “万众创新” 的建设, 文中 从创新素质, 创新案例教育、创新氛围保证、 创新成果激励进行了论述, 以期为职业院校 创新教育事实提供参考。

\section{2. 职业技术学校实现创新教育的途径}

\section{1 创新素质是创新人才的关键}

创新素质包括创新品质、创新思维和创 新能力。是能够打破常规、突破传统, 具有 敏锐的洞察力、直觉力、丰富的想像力、预 测力和捕捉机会的能力等, 从而使思维具有 一种超前性、变通性。创新素质的形成与发 展是一个长期内化工程, 有了较高的素质就 会在认识世界和改造世界的活动中表现出 较强的适应力和创造力。因此, 创新型人才 培养要全面提高学生的创新素质。培养学生 乐于接受新观念, 善于打破常规和善于思 考。培养学生探究内核的毅力, 不怕困难和 失败, 只有这样的学生才会释放更好的创新 灵感, 产生更新颖、更独特的想法[3][4]。

创新品质是创新活动的内在动力机构。 包括创新精神、创新意识、创新人格。创新 精神指推崇创新, 追求创新, 以创新为荣; 创新意识是指善于发现并提出问题, 具有强 烈的 “问题意识”; 创新人格指具有好奇心、 求知欲, 具有献身科学、献身人类事业的内 在动力和坚强意志, 具有敢闯、敢冒风险、 敢于怀疑和批判的科学精神, 具有良好的精 神状态和心理素质。

创造性思维是人的一种独立的思维形 式, 是人类所特有的, 它是人在强烈的创造 意识支配下, 将大脑中已有的感性和理性知 识信息, 按科学思路, 借助于想象和直觉进 行的重建、组合和升华, 最终以严密的辩证 逻辑所完成的思维活动的过程。
创新能力属于创新活动的工作机构。具 备宽广而扎实的基础知识, 广阔的视野, 以 及善于综合开拓新领域的能力, 掌握创新知 识的方法论, 尤其是具备良好的创造技能, 包括一般工作能力和动手能力, 熟练掌握和 运用创造技法的能力, 创新成果的表达能力 （论文写作）、表现能力（艺术创作）和物 化能力（创造设想物化为模型和产品）。

没有强烈的创新意识, 便不能运用发散 性思维获得猜想, 创新活动便无从谈起。创 新素质教育, 是全面培养学生的创新思维和 创新人格。教会学生解决问题时, 重视的不 是结果, 而是过程中的思考, 因此, 在教学 过程中, 关键是要有效地调动学生的创新积 极性, 激发他们的新思想、新设计和对问题 的质疑。比如目前的红酒瓶塞与开瓶器是分 开的, 操作起来麻烦, 而有的时候会很难将 红酒开启。因此, 如果设计出一种简易的瓶 塞, 直接调整瓶塞内部的机构即可将瓶塞拧 紧或者松动, 对实际生活很重要。为此设计 了一种新型多点膨胀红酒瓶塞, 直接调整瓶 塞的内部机构即可将瓶塞拧紧或者松动, 可 以快速的实现红酒瓶塞的密封和开启,具体 见图1。

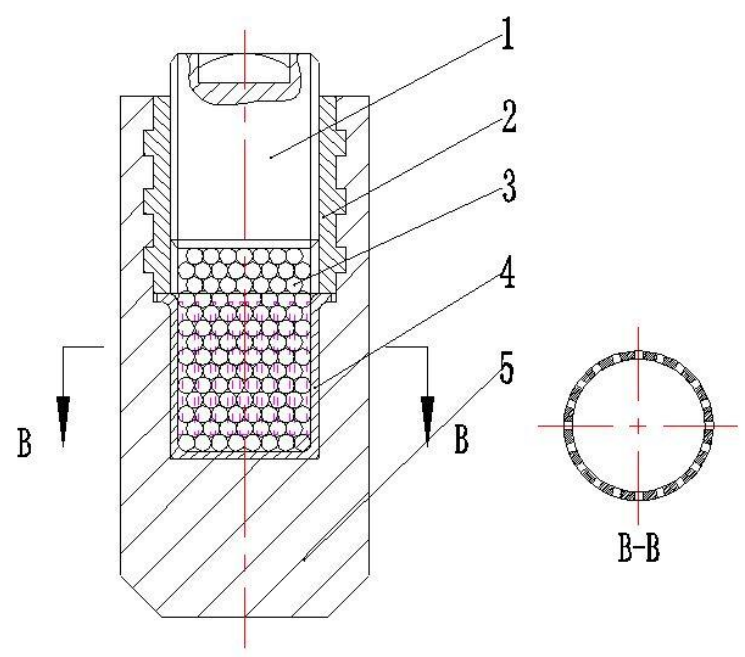

1.螺纹塞 2.套 3.玻璃珠子 4.弹性筒 5.瓶塞

图1 新型多点膨胀式红酒瓶塞设计

\section{2 创新案例教育是开启创新的基础}

采用以专题案例为中心的学习模式, 首 先以机械类创新案例为模式分析, 解析内 核, 然后根据要求设计具有挑战性的专题, 由学生自己根据专题设计内容, 成立个人学 习或小组研究。由学生自己进行自我评估, 
给出专题研究进展和存在问题, 并提交讨 论, 在这个过程中, 教师可随时给学生以协 助和引导。比如结合机械专业给出了一个专 题: 如何实现传动轴上传动齿的快速夹紧装 置, 不同的学生提出了不同的想法, 并设计 了相应结构。通过锁紧螺套推动圆环, 再推 动挡板以及弹簧垫片, 进而对三个雉面楔块 施加压力, 由于三个锥面楔块与齿轮内壁之 间的力的作用, 会使三个雉面楔快既有横向 运动, 又有径向运动, 从而将传动轴夹紧, 具体如图2所示。

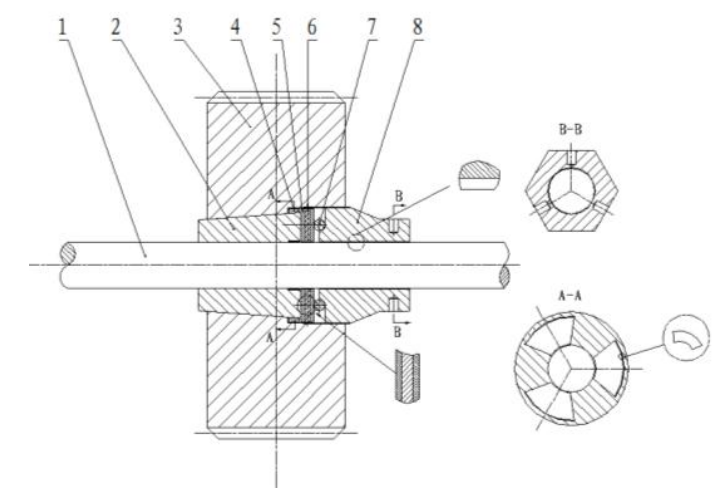

1.传动轴 2. 锥面楔块 3.齿轮 4. 固定块 5. 挡板 6 .

弹簧垫圈 7. 圆环 8.锁紧螺套

图2 传动轴的快速夹紧装置设计

\section{3 创新成果激励是推进创新动力}

(1) 知识产权推动 知识产权指 “权利人对 其所创作的智力劳动成果所享有的专有权 利” ，一般只在有限时间期内有效。专利作 为知识产权的形式, 它是对创新成果认可、 对创新者成果的一种保护。因此, 专利授权 是衡量一个学校创新能力的指标, 也是职业 院校通过技术创新, 提高内涵的重要形式。 但制造类职业院校在知识产权和专利申请 上积极性不够, 因此, 积极推动以创新驱动、 专利申请的战略是推动制造类院校技术创 新能力的重要手段。

学生申请专利获得授权是核心, 它可 以极大提升学生的积极性, 例如我校制造工 程系从2010年开始学生创新工作, 目前学生 以第一发明人获授权专利 12 项, 申请专利 10 项, 涉及学生 100 人。

(2) 创新实践趋动 通过创新实践积极引 导、鼓励学生参与大学生创新、大学生科研 训练计划等, 培养他们的科研热情, 鼓励学 生参加校内外各种创新性竞赛, 特别是校
级、市级、省级、国家级职业技能大赛, 营 造勇于探索、敢于创新的品质。通过创新实 践提升创新内涵, 通过创新实践深化所学专 业知识和技能, 通过创新实践体现学生的社 会价值。通过创新实践获得的创新成果如大 赛获奖、发表论文、奖励等提升创新动力。

例如, 2011年我校在制造工程系建立了 学生创新社团, 由专人教师带队给予指导, 目前已获得16项市级、校级、院级大学生创 新科研项目支持, 开发样机6台。

总之, 创新成果是推动创新型人才培养 的动力, 多层次的创新实践是获得创新成果 的基础, 创新成果是推进学生自由思维、自 由表达和自由讨论的动力, 会让思想的火花 在宽松的空间碰撞出更多的 “新物质”。

\section{4 创新氛围是创新教育培养的土壤}

良好的创新氛围是创新能力培养的土 壤, 创新教育氛围和创新人才之间存在着相 互作用的辩证发展关系, 创新教育氛围培育 创新人才, 反之, 创新人才又改变创新教育 环境。创新型人才的培养离不开教育氛围、 家庭氛围和社会氛围。在这些氛围因素中, 教育氛围, 特别是大学教育氛围是十分重要 的[2][4]。良好的教育氛围, 是高校培育创 新精神的基础和前提, 也是判断一所学校是 否真正推行素质教育的试金石。创新氛围建 设所折射出的是一个学校体现时代要求的 品位和格调。这就要求高等学校必须营造一 种创新教育的良好土壤和氛围, 让学生在这 种氛围中成为一个真正具有创新能力的人。

创新氛围首先要坚持多样性教育, 将差 异性与多样性结合。多样性的教育就是充分 考虑和尊重学生的差异, 注重调动学生求知 的主动性和创造性, 激发和培养学生的学习 热情, 使学生的专长得到充分发展。更重要 的是, 多样性的教育遵循以人为本的教育理 念, 把学生作为教育的主体, 以学生为核心, 着眼学生的未来发展、创新、求异思维。一 个充满多样性, 允许多样化发展的良好氛围 才更具活力, 才会为更多的创造性人才脱颖 而出创造条件。

例如每年一度的全国职业技能大赛, 我 小通过选拔优秀选手参加, 以彰显学校的教 学实践水平, 通过大赛引导教育改革。如 2011年全国职业院校技能大赛高职组“机械 
部件创新设计与制造” 竞赛项目, 给定一风 能, 根据能量转换原理, 创新设计与制造一 风能驱动叶轮转动, 进而带动传动机构和驱 动机构, 实现物料传送的机械装置[3][4]。 共包括三部分: 创新设计, 创新制造, 现场 答辩。这一比赛形式将赛技能转向以完成具 有一定功能的产品转化, 突出整体性、系统 性和创新性。从参赛单位的 40 多个队的比赛 结果看, 没有两个对是相同的, 大家设计各 有特色, 让人大开眼界。下面图 3 就是其中 1 个典型的风力驱动结构。另外, 对其他不参 加国赛的学生设计了校级技能节项目、各级 创新社团等氛围, 以提高创新能力。

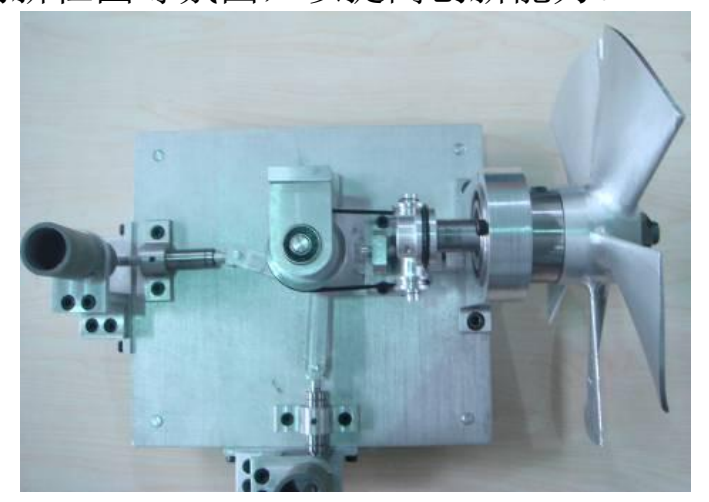

图3带轮驱动

其次要构建和谐的育人氛围。培养创新 型人才, 必须注重学生的个性发展, 保护和 开发学生的好奇心和创造欲, 发展学生的潜 能。提倡在大学的课堂里, 营造民主宽松的 教学氛围。教师要充分尊重学生的思想和情 感的释放, 使之能在平等和轻松的气氛中充 分表现展现自己的想法, 形成教与学的相 长。这样宽松、和谐、允许风险和失败的的 校园氛围, 将会孕育出更多的具有创新思维 的学生。例如真对游戏高手学生, 要求真对 玩家的电脑机箱: 提供一种能在周围环境热 或冷都能有效保证CPU温度恒定的机箱。在 开机时, 油泵就开始运作, 机箱内的油就开 始流动, 大幅度降低显卡与主板的温度, 显 卡温度过高时, 油会在循环的过程中通过冷 却装置, 被冷排与半导体降温, 继而保持 CPU温度恒定, 还可以进行循环利用, 保持 CPU运行稳定。

最后创新制度建设是保障, 创新必须有 制度和机制作保障, 没有制度建设, 创新不 可能持久, 更不可能形成创新的氛围。高校
应该通过制度的规范作用, 使学生善于接受 新知识、乐于运用新知识、勇于创造新知识, 形成人才辈出的生动局面。

\section{3. 结束语}

实施创新教育是一项长远的工程, 它需 要制度支持、氛围保证、教师的协作外, 要破除传统的思维习惯, 要有打破传统, 进 行飞跃的魄力。职业院校开展创新教育, 目 的在于培养学生的创造性思维能力, 应用知 识的能力。总之, 实施创新教育一定要坚持 以提高学生素质为中心, 以创新品质、创新 思维和创新能力为核心, 通过创新案例驱 动、创新氛围保证、创新成果激励等，以推 动职业院校学生教育的实施, 为万众创新提 供支持，为中国制造2025提供保障。

\section{致谢}

本文获得上海工程技术大学教研项目 ( No. A-2512-10-1308) 和 (No. A1-0601-15-0175)支持。

\section{References}

[1]http://news.china.com/domestic/945/20150 519/19710486.html

[2] Jitao Du. Analysis of Innovating Education methods for Advanced Vocational Colleges[C], 2011 International Conference on Education and Education Mangement, pp.215-219, 2011.

[3] Jitao Du. Consideration for Graduate Design Selecting Topics of Advanced Vocational Colledges[C], 2011 International Conference on Education and Education Mangement, pp. 220-223, 2011.

[4] Jitao Du. Driving By Innovation Mechanical Speciality Teaching Mode Reformation [C], 2012 International Coference on Enigineering and Business Management, Shanghai. pp.37-40, 2012. 